\title{
Graceful and Skolem graceful Labeling in Extended Duplicate Graph of Path
}

\author{
P. P. Ulaganathan, K. Thirusangu, and B. Selvam \\ Department of Mathematics, S.I.V.E.T. College, Gowrivakkam, Chennai-600 073, India \\ ppulaganathan@gmail.com, kthirusangu@gmail.com, chellamaths@yahoo.com
}

\begin{abstract}
In this paper, we prove that the Extended Duplicate Graph of Path is Graceful and Skolem-graceful. AMS subject classification: $05 \mathrm{C} 78$
\end{abstract}

Keywords: Graph labeling, Graceful labeling, Skolem-graceful labeling, Extended Duplicate Graph.

\section{Introduction}

In 1967, the concept of graph labeling was introduced by Rosa (1997). Graph labeling is an assignment of integers to the edges or vertices or both subject to certain conditions. Labeled graphs serve as useful models in a broad range of applications such as circuit design, communication network addressing, X-ray crystallography, radar, astronomy, data base management and coding theory. Over the past three decades various labeling of graphs such as cordial labeling, prime labeling, binary labeling, magic labeling, anti-magic labeling, bi-magic labeling, mean labeling, arithmetic labeling, graceful labeling, harmonious labeling etc., have been investigated in the literature (Gallian, 2010). Golomb has introduced graceful labeling (Golomb, 1972). In 1989 Gallian showed that all mobius ladders are graceful. Aravamudhan and Murugan have shown that the complete tripartite graph $\mathrm{K}_{1, \mathrm{~m}, \mathrm{n}}$ is both graceful and harmonious. Lee has introduced Skolem-graceful labeling. Lee et al. (1988) have shown that a connected graph is skolem-graceful if and only if it is a graceful tree (Lee et al., 1988). They also proved that the disjoint union of 2 or 3 stars is skolem-graceful if and only if atleast one star has even size. Youssef (2003) proved that if $G$ is skolem-graceful then $G+\bar{K}_{n}$ is graceful (Youssef, 2003). In Youssef (2003) it is proved that extended duplicate graph of paths are cordial. Though graceful labeling and Skolem-graceful labeling have been studied for different kinds of graphs, the graceful and skolemgraceful labeling for duplicate graphs have not been investigated. In this paper we prove that extended duplicate graph of path graphs are graceful and Skolem graceful.

\section{Preliminaries}

In this section, we give the basic notions relevant to this paper. Let $G=G(V, E)$ be a finite, simple and undirected graph with $p$ vertices and $q$ edges. By a labeling we mean one-to-one mapping that carries a set of graph elements onto a set of numbers, called labels (usually the set of integers). In this paper we deal labeling with domain as the set of all vertices.
Definition: $A$ function $f$ is said to be graceful of a graph $G$ with q-edges if $f$ is $1-1$ from $\mathrm{V} \rightarrow\{0,1,2, \ldots, \mathrm{q}\}$ such that for each edge $x y$ assigned the label $|f(x)-f(y)|$, the resulting edge labels are distinct numbers $\{1,2, \ldots, q\}$.

Definition: A ( $p, q)$ graph $G$ is called Skolem-graceful if there exists 1-1 map $f: \mathrm{V} \rightarrow\{1,2, \ldots, \mathrm{p}\}$ such that the edge labels induced by $|f(x)-f(y)|$ for each $x y$ are $1,2, \ldots$, q. This is also called node-graceful. A necessary condition for a graph to be Skolem-graceful is that $p \geq q+1$.

Definition: Let $\mathrm{G}(\mathrm{V}, \mathrm{E})$ be a simple graph. A duplicate graph of $G$ is $D G=\left(V_{1}, E_{1}\right)$ where the vertex set $V_{1}=V \cup$ $\mathrm{V}^{\prime}$ and $\mathrm{V} \cap \mathrm{V}^{\prime}=\phi$ and $f: \mathrm{V} \rightarrow \mathrm{V}^{\prime}$ is bijective (for $\mathrm{V} \in \mathrm{V}$, we write $f(v)=v^{\prime}$ for convenience) and the edge set $E_{1}$ of $D G$ is defined as follows: The edge $a b$ is in $E$ if and only if both $a b^{\prime}$ and $a^{\prime} b$ are edges in $E_{1}$. Clearly the duplicate graph of the path graph is disconnected. We give the following definition from (Thirusangu et al., 2010).

Definition: Let $D G=\left(V_{1}, E_{1}\right)$ be a duplicate graph of the path graph $G(V, E)$. We add an edge between any one vertex from $V$ to any other vertex in $V^{\prime}$, except the terminal vertices of $\mathrm{V}$ and $\mathrm{V}^{\prime}$. For convenience, let us take $\mathrm{v}_{2} \in \mathrm{V}$ and $v_{2}^{1} \in \mathrm{V}^{\prime}$ and thus the edge $\left(\mathrm{v}_{2}, v_{2}^{1}\right)$ is formed. This graph is called the extended duplicate graph of the path $P_{m}$ and it is denoted by EDG $\left(P_{m}\right)$.

\section{Main results}

Graceful labeling for EDG $\left(P_{m}\right)$ : In this section, we present an algorithm and prove the existence of graceful labeling for EDG $\left(P_{m}\right)$.

\section{Algorithm:}

Input: EDG $\left(P_{m}\right)$ with $p$ vertices and $q$ edges where $p=$ $(2 \mathrm{~m}+2), \mathrm{q}=(2 \mathrm{~m}+1)$.

Step 1: Denote the $(2 \mathrm{~m}+2)$ vertices as $\mathrm{V}=\left\{v_{1}, v_{2}, \ldots, v_{\mathrm{m}}\right.$, $\left.v_{\mathrm{m}+1}, v_{1}^{\prime}, v_{2}^{\prime} \ldots v_{m}^{\prime}, v_{m+1}^{\prime}\right\}$.

Step 2: If ' $\mathrm{m}$ ' is even, then $\mathrm{m}=2 \mathrm{n} ; n \in \mathrm{N}$. The EDG $\left(\mathrm{P}_{\mathrm{m}}\right)$ is of the form

$\operatorname{EDG}\left(\mathrm{P}_{2 \mathrm{n}}\right) ; n \in \mathrm{N}$.

Define $f: \mathrm{V} \rightarrow\{0,1,2, \ldots, \mathrm{q}\}$ such that
Research article

CIndian Society for Education and Environment (iSee)
"Skolem-Graceful labeling" http://www.indjst.org
Ulaganathan et al. Indian J.Sci.Technol. 
Indian Journal of Science and Technology

$f\left(v_{2 i+1}\right)=\mathrm{i} ; \quad 0 \leq \mathrm{i} \leq \mathrm{m} / 2$

$f\left(v_{2 i+2}\right)=\mathrm{m}-\mathrm{i} ; 0 \leq \mathrm{i} \leq(\mathrm{m}-2) / 2$

$f\left(v_{2 i+1}^{\prime}\right)=(m+1)+i ; 0 \leq i \leq m / 2$

$f\left(v_{2 i+2}^{\prime}\right)=(2 \mathrm{~m}+1)-\mathrm{i} ; 0 \leq \mathrm{i} \leq(\mathrm{m}-2) / 2$

Step 3: If ' $\mathrm{m}$ ' is odd, then $\mathrm{m}=2 \mathrm{n}+1 ; n \in \mathrm{N}$.

The EDG $\left(P_{m}\right)$ is of the form EDG $\left(P_{2 n+1}\right) ; n \in N$.

Define $f: \mathrm{V} \rightarrow\{0,1,2, \ldots, \mathrm{q}\}$ such that

$f\left(v_{2 i+1}\right)=\mathrm{i} ; 0 \leq \mathrm{i} \leq(\mathrm{m}-1) / 2$

$f\left(v_{2 i+2}\right)=m-i ; 0 \leq i \leq(m-1) / 2$

$f\left(v_{2 i+1}^{\prime}\right)=(\mathrm{m}+1)+\mathrm{i} ; 0 \leq \mathrm{i} \leq(\mathrm{m}-1) / 2$

$f\left(v_{2 i+2}^{\prime}\right)=(2 \mathrm{~m}+1)-\mathrm{i} ; 0 \leq \mathrm{i} \leq(\mathrm{m}-1) / 2$

Step 4: Define $f^{*}: \mathrm{E} \rightarrow \mathrm{N}$ such that $f^{*}\left(v_{\mathrm{i}}, v_{\mathrm{j}}\right)=$

$$
\left|f\left(v_{i}\right)-f\left(v_{\mathrm{j}}\right)\right|
$$

\section{Output: Graceful labeling of EDG $\left(\mathrm{P}_{\mathrm{m}}\right)$}

Theorem: The extended duplicate graph of path $\mathrm{P}_{\mathrm{m}}$, $m \geq 2$ admits graceful labeling.

Proof: Let EDG $\left(P_{m}\right)$ be a Extended duplicate graph of path $P_{m}$. Clearly EDG $\left(P_{m}\right)$ has $p$ vertices and $q$ edges where

$p=(2 m+2), q=(2 m+1)$. Denote the set of vertices as

$V=\left\{v_{1}, v_{2}, \ldots, v_{\mathrm{m}}, v_{\mathrm{m}+1}, v_{1}^{\prime}, v_{2}^{\prime} \ldots v_{m}^{\prime}, v_{m+1}^{\prime}\right\}$

Case 1: In this case, we prove this theorem for even paths. Let $\mathrm{P}_{\mathrm{m}}$ be a path, where $\mathrm{m}=2 \mathrm{n} ; n \in \mathrm{N}$.

Consider the paths of the type $\mathrm{P}_{2 n} ; n \in \mathrm{N}$. In this case, we get path graphs $P_{2}, P_{4}, P_{6}, \ldots$

To get graceful labeling, define a map $f: \bigvee \rightarrow\{0,1,2$, ..., q\} as given in step 2 of the above algorithm.

Therefore the vertices $v_{1}, v_{3}, v_{5}, \ldots, v_{\mathrm{m}+1}, v_{\mathrm{m}}, v_{\mathrm{m}-2}, \ldots, v_{2}$ receive consecutive numbers such as $0,1,2, \ldots, \mathrm{m}$ as labels and $v_{1}^{\prime}, v_{3}^{\prime}, v_{5}^{\prime} \ldots v_{m+1}^{\prime}, v_{m}^{\prime}, v_{m-2}^{\prime}, \ldots, v_{2}^{\prime}$ receive consecutive numbers such as $\mathrm{m}+1, \mathrm{~m}+2, \ldots, 2 \mathrm{~m}+1$.

Thus all the $(2 m+2)$ vertices are labeled.

From the definition of EDG $\left(P_{m}\right)$, the $(2 m+1)$ edges of EDG $\left(P_{m}\right)$ are of the form $\left(v_{i}, v_{i+1}^{\prime}\right)\left(v_{i}^{\prime}, v_{i+1}\right)$ for $i=1,2, \ldots$, $\mathrm{m}$ and $\left(v_{2}, v_{2}^{\prime}\right)$. Define induced function $f^{*}: \mathrm{E} \rightarrow \mathrm{N}$ such that $f^{*}\left(v_{i}, v_{\mathrm{j}}\right)=\left|f\left(v_{\mathrm{i}}\right)-f\left(v_{\mathrm{j}}\right)\right|$
Vol. 4 No. 2 (Feb 2011)

ISSN: 0974- 6846

Now the edges are labeled as follows: The edges are in the following five forms, namely, $\left(v_{2 i+1}, v_{2 i+2}^{\prime}\right), \quad\left(v_{2 i+1}^{\prime}\right.$ , $\left.v_{2 i+2}\right)$ where $0 \leq \mathrm{i} \leq(\mathrm{m}-2) / 2 ; \quad\left(v_{2 i+2}, v_{2 j+1}^{\prime}\right),\left(v_{2 i+2}^{\prime}, v_{2 j+1}\right)$ where $\mathrm{j}=\mathrm{i}+1,0 \leq \mathrm{i} \leq(\mathrm{m}-2) / 2$ and $\left(v_{2}, v_{2}^{\prime}\right)$.

For any $\mathrm{i}$, where $0 \leq \mathrm{i} \leq(\mathrm{m}-2) / 2$,

$$
f^{*}\left(v_{2 i+1}, v_{2 i+2}^{\prime}\right)=\left|f\left(v_{2 i+1}\right)-f\left(v_{2 i+2}^{\prime}\right)\right|=|2 \mathrm{i}-(2 \mathrm{~m}+1-\mathrm{i})|
$$

$=|\mathrm{q}-2 \mathrm{i}|$ which is an odd number $\forall \mathrm{i}$

These $\mathrm{m} / 2$ edges are labeled with numbers $\mathrm{q}, \mathrm{q}-2, \mathrm{q}-4, \ldots$, $(q+5) / 2$.

For any $\mathrm{i}$, where $0 \leq \mathrm{i} \leq(\mathrm{m}-2) / 2$,

$$
f^{*}\left(v_{2 i+1}^{\prime}, v_{2 i+2}\right)=|\{(\mathrm{m}+1)+\mathrm{i}\}-(\mathrm{m}-\mathrm{i})|
$$

$=|2 \mathrm{i}+1|$ which is an odd number $\forall \mathrm{i}$

These $\mathrm{m} / 2$ edges are labeled with numbers $1,3,5, \ldots$, $(\mathrm{q}-3) / 2$.

Let $\mathrm{j}=\mathrm{i}+1$, for any $\mathrm{i}$, where $0 \leq \mathrm{i} \leq(\mathrm{m}-2) / 2$,

$f^{*}\left(v_{2 i+2,} v_{2 j+1}^{\prime}\right)=\left|f\left(v_{2 i+2}\right)-f\left(v_{2 j+1}^{\prime}\right)\right|=$

$|(m-i)-(m+1+j)|$

$=|2 \mathrm{i}+2|$ which is an even number $\forall \mathrm{i}$

These $\mathrm{m} / 2$ edges are labeled with numbers $2,4,6, \ldots$, $(\mathrm{q}-1) / 2$.

Let $\mathrm{j}=\mathrm{i}+1$, for any $\mathrm{i}$, where $0 \leq \mathrm{i} \leq(\mathrm{m}-2) / 2$,

$f^{*}\left(v_{2 i+2}^{\prime}, v_{2 j+1}\right)=\left|f\left(v_{2 i+2}^{\prime}\right)-f\left(v_{2 j+1}\right)\right|=|(2 m+1-i)-j|$

$=|(q-1)-2 i|$ which is an even number $\forall \mathrm{i}$

These $m / 2$ edges are labeled with numbers $q-1, q-3, q-5$, ..., $(\mathrm{q}+3) / 2$.

For the edge $\left(v_{2}, v_{2}^{\prime}\right)$,

$f^{*}\left(v_{2}, v_{2}^{\prime}\right)=\left|f\left(v_{2}\right)-f\left(v_{2}^{\prime}\right)\right|=|\mathrm{m}-(2 \mathrm{~m}+1)|$

$=(\mathrm{q}+1) / 2$ which is also an odd number.

Thus the edges $\left(v_{1}^{\prime}, v_{2}\right),\left(v_{2}, v_{3}^{\prime}\right),\left(v_{3}^{\prime}, v_{4}\right), \ldots$,

$\left(v_{\mathrm{m}}, v_{m+1}^{\prime}\right)$ receive consecutive numbers such as $1,2, \ldots$, $(\mathrm{q}-1) / 2$ as labels; the edge $\left(v_{2}, v_{2}^{\prime}\right)$ receives the number $(\mathrm{q}+1) / 2$ as label and $\left(v_{\mathrm{m}+1}, v_{m}^{\prime}\right),\left(v_{m}^{\prime}, v_{\mathrm{m}-1}\right), \ldots,\left(v_{2}^{\prime}, v_{1}\right)$ receive consecutive numbers such as $(q+3) / 2,(q+5) / 2, \ldots$, q as labels.

That is $f^{*}(\mathrm{E})=\{1,2,3, \ldots, \mathrm{q}\}$ which are all distinct and hence EDG $\left(P_{m}\right)$ is graceful.

Case (2): In this case, we prove this theorem for odd paths. Let $\mathrm{P}_{\mathrm{m}}$ be a path, where $\mathrm{m}=2 \mathrm{n}+1 ; n \in \mathrm{N}$.

Consider the paths of the type $\mathrm{P}_{2 n+1} ; n \in \mathrm{N}$. In this case, we get path graphs $P_{3}, P_{5}, P_{7}, \ldots$.

To get graceful labeling, define a map $f: \bigvee \rightarrow\{0,1,2$, ..., q\} as given in step 3 of the above algorithm.

Therefore the vertices $v_{1}, v_{3}, v_{5}, \ldots v_{\mathrm{m}}, v_{\mathrm{m}+1}, v_{\mathrm{m}-1}, v_{\mathrm{m}-3}, \ldots$, $v_{2}$ receive consecutive numbers such as $0,1,2, \ldots \mathrm{m}$ as
Ulaganathan et al. Indian J.Sci.Technol. 
Indian Journal of Science and Technology

labels and $v_{1}^{\prime}, v_{3}^{\prime}, \ldots v_{m}^{\prime}, v_{m+1}^{\prime}, v_{m-1}^{\prime}, v_{m-3}^{\prime}, \ldots, v_{2}^{\prime}$ receive consecutive numbers such as $\mathrm{m}+1, \mathrm{~m}+2, \ldots, 2 \mathrm{~m}+1$ as

Annexure I. Graceful labeling.

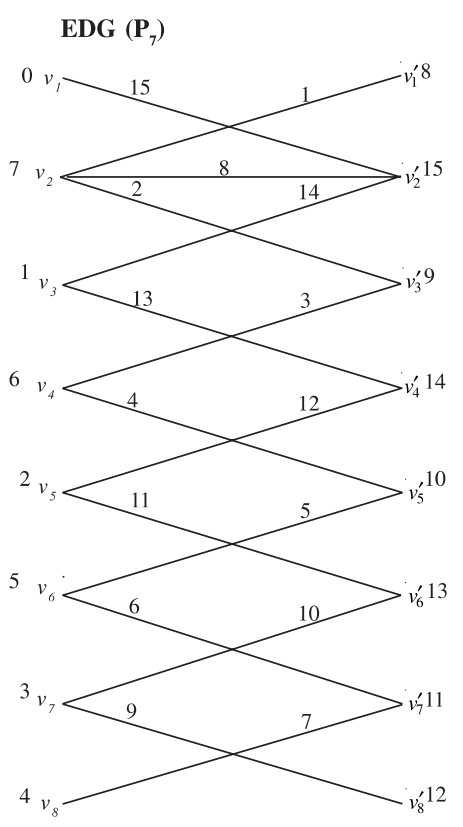

EDG $\left(\mathbf{P}_{8}\right)$

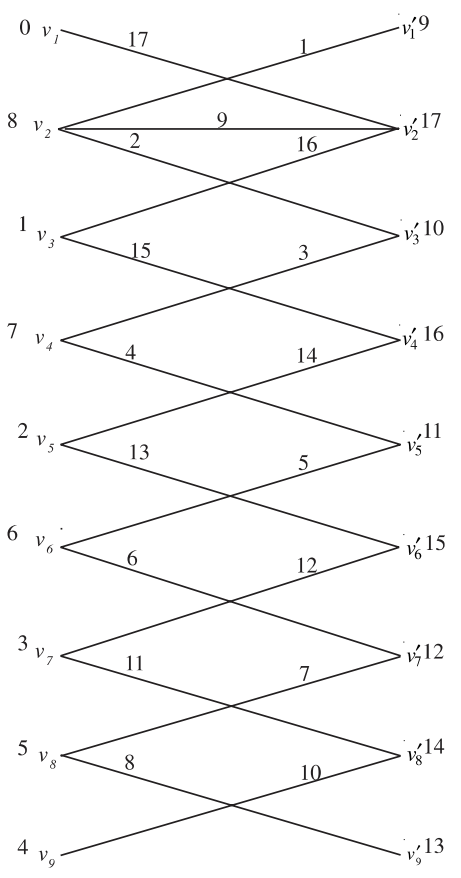

labels.

Thus all the $(2 m+2)$ vertices are labeled.

Define induced function $f^{*}: \mathrm{E} \rightarrow \mathrm{N}$ such that $f^{*}\left(v_{\mathrm{i}}, v_{\mathrm{j}}\right)=$ $\left|f\left(v_{\mathrm{i}}\right)-f\left(v_{\mathrm{j}}\right)\right|$

Now the edges are labeled as follows: The edges are in the following five forms, namely, $\left(v_{2 i+1}, v_{2 i+2}^{\prime}\right)$,

$\left(v_{2 i+1}^{\prime}, v_{2 i+2}\right)$ where $0 \leq \mathrm{i} \leq(\mathrm{m}-1) / 2 ;\left(v_{2 i+2}, v_{2 j+1}^{\prime}\right)$,

$\left(v_{2 i+2}^{\prime}, v_{2 j+1}\right)$ where $\mathrm{j}=\mathrm{i}+1,0 \leq \mathrm{i} \leq(\mathrm{m}-3) / 2$ and $\left(v_{2}, v_{2}^{\prime}\right)$.

For any $\mathrm{i}$, where $0 \leq \mathrm{i} \leq(\mathrm{m}-1) / 2$,

$f^{*}\left(v_{2 i+1}, v_{2 i+2}^{\prime}\right)=\left|f\left(v_{2 i+1}\right)-f\left(v_{2 i+2}^{\prime}\right)\right|=|\mathrm{i}-(2 \mathrm{~m}+1-\mathrm{i})|$

$=|(\mathrm{q}-2 \mathrm{i})|$ which is an odd number $\forall \mathrm{i}$.

These $(m+1) / 2$ edges are labeled with numbers as $q, q-2$, $\mathrm{q}-4, \ldots,(\mathrm{q}+3) / 2$.

For any $\mathrm{i}$, where $0 \leq \mathrm{i} \leq(\mathrm{m}-1) / 2$,

$f^{*}\left(v_{2 i+1}^{\prime}, v_{2 i+2}\right)=\left|f\left(v_{2 i+1}^{\prime}\right)-f\left(v_{2 i+2}\right)\right|=\mid(m+1+\mathrm{i})-$

$(\mathrm{m}-\mathrm{i}) \mid$

$=|2 i+1|$ which is an odd number $\forall \mathbf{i}$

These $(m+1) / 2$ edges are labeled with numbers as $1,3,5, \ldots,(\mathrm{q}-1) / 2$.

Let $\mathrm{j}=\mathrm{i}+1$, for any $\mathrm{i}$, where $0 \leq \mathrm{i} \leq(\mathrm{m}-3) / 2$,

$f^{*}\left(v_{2 i+2,} v_{2 j+1}^{\prime}\right)=\left|f\left(v_{2 i+2}\right)-f\left(v_{2 j+1}^{\prime}\right)=\right|(m-i)-(m+1+j) \mid$
$=|2 i+2|$ which is an odd number $\forall \mathbf{i}$

These $(m-1) / 2$ edges are labeled with numbers as $2,4,6$, ..., $(q-3) / 2$.

For any $\mathrm{i}$, where $0 \leq \mathrm{i} \leq \mathrm{m}-3 / 2$,

$f^{*}\left(v_{2 i+2}^{\prime}, v_{2 j+1}\right)=\left|f\left(v_{2 i+2}^{\prime}\right)-f\left(v_{2 j+1}\right)\right|=|(2 m+1-i)-j|$

$=|(\mathrm{q}-1)-2 \mathrm{i}|$ which is an even number $\forall \mathbf{i}$

These $(m-1) / 2$ edges are labeled with numbers as $q-1$, $\mathrm{q}-3, \mathrm{q}-5, \ldots,(\mathrm{q}+5) / 2$.

For the edge $\left(v_{2}, v_{2}^{\prime}\right)$,

$f^{*}\left(v_{2}, v_{2}^{\prime}\right)=\left|f\left(v_{2}\right)-f\left(v_{2}^{\prime}\right)\right|=|\mathrm{m}-(2 \mathrm{~m}+1)|$

$=(q+1) / 2$ which is also an even number.

Thus the edges $\left(v_{1}^{\prime}, v_{2}\right),\left(v_{2}, v_{3}^{\prime}\right)\left(v_{3}^{\prime}, v_{4}\right) \ldots\left(v_{m}^{\prime}\right.$, $\left.v_{m+1}\right)$ receive consecutive numbers such as $1,2, \ldots$,

$(\mathrm{q}-1) / 2$ as labels; the edge $\left(v_{2}, v_{2}^{\prime}\right)$ receives the number $(q+1) / 2$ as label and the edges $\left(v_{m+1}^{\prime}, v_{m}\right)$,

$\left(v_{\mathrm{m}}, v_{m-1}^{\prime}\right),\left(v_{m-1}^{\prime}, v_{\mathrm{m}-2}\right), \ldots,\left(v_{2}^{\prime}, v_{1}\right)$ receive consecutive numbers such as $(\mathrm{q}+3) / 2,(\mathrm{q}+5) / 2, \ldots, \mathrm{q}$ as labels.

That is $f^{*}(\mathrm{E})=\{1,2,3, \ldots, \mathrm{q}\}$ which are all distinct and hence EDG $\left(P_{m}\right)$ is graceful.

Illustration: Graceful labeling for the graphs EDG $\left(\mathrm{P}_{7}\right)$ and EDG $\left(\mathrm{P}_{8}\right)$ are shown in the annexure I.

\section{Skolem-graceful labeling for EDG $\left(P_{m}\right)$}

In this section, we present an algorithm and prove the existence of Skolem-Graceful labeling for EDG $\left(P_{m}\right)$.

Algorithm:

Input: EDG $\left(P_{m}\right)$ with $p$ vertices and $q$ edges where $p=$ $(2 m+2), q=(2 m+1)$.

Step 1: Denote the $(2 \mathrm{~m}+2)$ vertices as $V=\left\{v_{1}, v_{2}, \ldots, v_{m}\right.$, $\left.v_{\mathrm{m}+1}, v_{1}^{\prime}, v_{2}^{\prime} \ldots v_{m}^{\prime}, v_{m+1}^{\prime}\right\}$

Step 2: If ' $\mathrm{m}$ ' is even, then $\mathrm{m}=2 \mathrm{n} ; n \in \mathrm{N}$. The EDG $\left(\mathrm{P}_{\mathrm{m}}\right)$ is of the form

$\operatorname{EDG}\left(\mathrm{P}_{2 n}\right) ; n \in \mathrm{N}$.

Define $f: \mathrm{V} \rightarrow\{1,2, \ldots, \mathrm{p}\}$

$f\left(v_{2 \mathrm{i}-1}\right)=\mathrm{i} ; \quad 1 \leq \mathrm{i} \leq(\mathrm{m}+2) / 2$

$f\left(v_{2 i}\right)=(m+2)-i ; 1 \leq \mathrm{i} \leq \mathrm{m} / 2$

$f\left(v_{2 i-1}^{\prime}\right)=(\mathrm{m}+1)+\mathrm{i} ; 1 \leq \mathrm{i} \leq(\mathrm{m}+2) / 2$

$f\left(v_{2 i}^{\prime}\right)=(2 \mathrm{~m}+3)-\mathrm{i} ; 1 \leq \mathrm{i} \leq \mathrm{m} / 2$

Step 3: If ' $m$ ' is odd, then $m=2 n+1 ; n \in N$.

The EDG $\left(P_{m}\right)$ is of the form EDG $\left(P_{2 n+1}\right) ; n \in N$. 
Indian Journal of Science and Technology

Define $f: \bigvee \rightarrow\{1,2, \ldots, p\}$

$f\left(v_{2 \mathrm{i}-1}\right)=\mathrm{i} ; 1 \leq \mathrm{i} \leq(\mathrm{m}+1) / 2$

$f\left(v_{2 i}\right)=(\mathrm{m}+2)-\mathrm{i} ; 1 \leq \mathrm{i} \leq(\mathrm{m}+1) / 2$

$f\left(v_{2 i-1}^{\prime}\right)=(\mathrm{m}+1)+\mathrm{i} ; 1 \leq \mathrm{i} \leq(\mathrm{m}+1) / 2$

$f\left(v_{2 i}^{\prime}\right)=(2 \mathrm{~m}+3)-\mathrm{i} ; 1 \leq \mathrm{i} \leq(\mathrm{m}+1) / 2$

Step 4: Define $f^{*}: \mathrm{E} \rightarrow \mathrm{N}$ such that $f^{*}\left(v_{\mathrm{i}}, v_{\mathrm{j}}\right)=$ $\left|f\left(v_{\mathrm{i}}\right)-f\left(v_{\mathrm{j}}\right)\right|$

Output: Skolem graceful labeling of EDG $\left(P_{m}\right)$

Theorem: The extended duplicate graph of path $\mathrm{P}_{\mathrm{m}}$,

$m \geq 2$ admits skolem - graceful labeling.

Proof: Let EDG $\left(P_{m}\right)$ be a Extended duplicate graph of path $P_{m}$. Clearly EDG $\left(P_{m}\right)$ has $p$ vertices and $q$ edges where $p=(2 m+2), q=(2 m+1)$.

Denote the set of vertices as $V=\left(v_{1}, v_{2}, \ldots, v_{m}, v_{m+1}\right.$, $\left.v_{1}^{\prime}, v_{2}^{\prime} \ldots v_{m}^{\prime}, v_{m+1}^{\prime}\right\}$

Case 1: In this case, we prove this theorem for even paths. Let $\mathrm{P}_{\mathrm{m}}$ be a path, when $\mathrm{m}=2 \mathrm{n} ; n \in \mathrm{N}$.

Consider the paths of the type $\mathrm{P}_{2 n} ; n \in \mathrm{N}$. In this case, we get path graphs $\mathrm{P}_{2}, \mathrm{P}_{4}, \mathrm{P}_{6}, \ldots$

To get the Skolem graceful labeling, define a map $f: \mathrm{V}$ $\rightarrow\{1,2, \ldots, p\}$ as given in step 2 of the above algorithm.

Therefore the vertices $v_{1}, v_{3}, v_{5}, \ldots, v_{\mathrm{m}+1}, v_{\mathrm{m}}, v_{\mathrm{m}-2}, \ldots, v_{2}$ receive consecutive numbers such as $1,2, \ldots,(m+1)$ as labels and $v_{1}^{\prime}, v_{3}^{\prime}, v_{5}^{\prime} \ldots v_{m+1}^{\prime}, v_{m}^{\prime}, v_{m-2}^{\prime}, \ldots, v_{2}^{\prime}$ receive consecutive numbers such as $\mathrm{m}+2, \mathrm{~m}+3, \ldots, 2 \mathrm{~m}+2$.

Thus all the $(2 m+2)$ vertices are labeled as $1,2,3, \ldots, p$.

From the definition of EDG $\left(P_{m}\right)$, the $(2 m+1)$ edges of EDG $\left(\mathrm{P}_{\mathrm{m}}\right)$ are of the form $\left(v_{\mathrm{i}}, v_{i+1}^{\prime}\right),\left(v_{i}^{\prime}, v_{\mathrm{i}+1}\right)$ for $\mathrm{i}=1,2, \ldots$, $\mathrm{m}$ and $\left(v_{2}, v_{2}^{\prime}\right)$.

Define the induced function $f^{*}: \mathrm{E} \rightarrow \mathrm{N}$ such that $f^{*}\left(v_{\mathrm{i}}, v_{\mathrm{j}}\right)$ $=\left|f\left(v_{\mathrm{i}}\right)-f\left(v_{\mathrm{j}}\right)\right|$

Now the edges are labeled as follows: The edges are in the following five forms, namely, $\left(v_{2 \mathrm{i}-1}, v_{2 i}^{\prime}\right),\left(v_{2 i-1}^{\prime}, v_{2 i}\right)$ where $1 \leq \mathrm{i} \leq \mathrm{m} / 2 ;\left(v_{2 i}, v_{2 j-1}^{\prime}\right),\left(v_{2 i}^{\prime}, v_{2 j-1}\right)$ where $\mathrm{j}=\mathrm{i}+1$,

$1 \leq \mathrm{i} \leq \mathrm{m} / 2$ and $\left(v_{2}, v_{2}^{\prime}\right)$.

For any $\mathrm{i}$, where $1 \leq \mathrm{i} \leq \mathrm{m} / 2$,

$f^{*}\left(v_{2 i-1}, v_{2 i}^{\prime}\right)=\left|f\left(v_{2 i-1}\right)-f\left(v_{2 i}^{\prime}\right)\right|=|\mathrm{i}-(2 \mathrm{~m}+3-\mathrm{i})|$
Vol. 4 No. 2 (Feb 2011)

ISSN: 0974- 6846

$=|(q+2)-2 i|$ which is an odd number $\forall i$

These $\mathrm{m} / 2$ edges are labeled with numbers $\mathrm{q}, \mathrm{q}-2, \mathrm{q}-4, \ldots$, $(q+5) / 2$.

For any $\mathrm{i}$, where $1 \leq \mathrm{i} \leq \mathrm{m} / 2$,

$f^{*}\left(v_{2 i-1}^{\prime}, v_{2 i}\right)=\left|f\left(v_{2 i-1}^{\prime}\right)-f\left(v_{2 i}\right)\right|=$

$|(m+1+i)-(m+2-i)|=|2 i-1|$ which is an odd number $\forall i$ These $\mathrm{m} / 2$ edges are labeled with numbers $1,3,5, \ldots$,

$(\mathrm{q}-3) / 2$.

Let $\mathrm{j}=\mathrm{i}+1$, for any $\mathrm{i}$, where $1 \leq \mathrm{i} \leq \mathrm{m} / 2$,

$f^{*}\left(v_{2 i,} v_{2 j-1}^{\prime}\right) \quad=\left|f\left(v_{2 i}\right)-f\left(v_{2 j-1}^{\prime}\right)\right|=$

$|(m+2-i)-(m+1+j)|=|2 i|$ which is an even number $\forall i$

These $\mathrm{m} / 2$ edges are labeled with numbers $2,4,6, \ldots$,

$(\mathrm{q}-1) / 2$.

Let $\mathrm{j}=\mathrm{i}+1$, for any $\mathrm{i}$, where $1 \leq \mathrm{i} \leq \mathrm{m} / 2$,

$f^{\star}\left(v_{2 i}^{\prime}, v_{2 j-1}\right)=\left|f\left(v_{2 i}^{\prime}\right)-f\left(v_{2 j-1}\right)\right|=|(2 m+3-\mathrm{i})-\mathrm{j}|$

$=|(q+1)-2 i|$ which is an even number $\forall i$

These $\mathrm{m} / 2$ edges are labeled with numbers |

$(\mathrm{q}+1)-2 \mathrm{i} \mid$ as $\mathrm{q}-1, \mathrm{q}-3, \mathrm{q}-5, \ldots,(\mathrm{q}+3) / 2$.

For the edge $\left(v_{2}, v_{2}^{\prime}\right)$,

$f^{*}\left(v_{2}, v_{2}^{\prime}\right)=\left|f\left(v_{2}\right)-f\left(v_{2}^{\prime}\right)\right|=|(m+2)-(2 m+3)|$

$=(q+1) / 2$ which is also an odd number.

Thus the edges $\left(v_{1}^{\prime}, v_{2}\right),\left(v_{2}, v_{3}^{\prime}\right),\left(v_{3}^{\prime}, v_{4}\right), \ldots$,

$\left(v_{\mathrm{m}}, v_{m+1}^{\prime}\right)$ receive consecutive numbers such as $1,2,3$, ..., (q-1)/2 as label; the edge $\left(v_{2}, v_{2}^{\prime}\right)$ receives the number $(\mathrm{q}+1) / 2$ as label and the edges $\left(v_{\mathrm{m}+1}, v_{m}^{\prime}\right),\left(v_{m}^{\prime}, v_{\mathrm{m}-1}\right), \ldots$, $\left(v_{2}^{\prime}, v_{1}\right)$ receive consecutive numbers such as $(q+3) / 2$, $(q+5) / 2, \ldots, q$ as labels.

That is $f^{*}(\mathrm{E})=\{1,2,3, \ldots, \mathrm{q}\}$ which are all distinct and hence EDG $\left(P_{m}\right)$ is Skolem graceful.

Case (2): In this case, we prove this theorem for odd paths. Let $\mathrm{P}_{\mathrm{m}}$ be a path, where $\mathrm{m}=2 \mathrm{n}+1 ; n \in \mathrm{N}$.

Consider the paths of the type $\mathrm{P}_{2 n+1} ; n \in \mathrm{N}$. In this case, we get path graphs $P_{3}, P_{5}, P_{7}, \ldots$.

To get the Skolem graceful labeling, define a map $f: \mathrm{V}$ $\rightarrow\{1,2,3, \ldots ., p\}$ as given in step 3 of the above algorithm.

Therefore the vertices $v_{1}, v_{3}, v_{5}, \ldots v_{\mathrm{m}}, v_{\mathrm{m}+1}, v_{\mathrm{m}-3}, \ldots, v_{2}$ receive consecutive numbers such as $1,2,3, \ldots, \mathrm{m}+1$ as labels and the vertices $v_{1}^{\prime}, v_{3}^{\prime}, \ldots v_{m}^{\prime}, v_{m+1}^{\prime}, v_{m-1}^{\prime}, v_{m-3}^{\prime}, \ldots, v_{2}^{\prime}$ receive consecutive numbers such as $m+2, m+3, \ldots,(2 m+2)$ as labels.

Thus all the $(2 m+2)$ vertices are labeled as $1,2,3, \ldots, p$.

Define induced function $f^{*}: \mathrm{E} \rightarrow \mathrm{N}$ such that $f^{*}\left(v_{\mathrm{i}}, v_{\mathrm{j}}\right)$ $=\left|f\left(v_{\mathrm{i}}\right)-f\left(v_{\mathrm{j}}\right)\right|$ 
Now the edges are labeled as follows: The edges are in the following five forms, namely, $\left(v_{2 i-1}, v_{2 i}^{\prime}\right)$, $\left(v_{2 i-1}^{\prime}, v_{2 i}\right)$ where $1 \leq \mathrm{i} \leq(\mathrm{m}+1) / 2 ; \quad\left(v_{2 i}, v_{2 j-1}^{\prime}\right),\left(v_{2 i}^{\prime}, v_{2 j-1}\right)$ where $\mathrm{j}=\mathrm{i}+1,1 \leq \mathrm{i} \leq(\mathrm{m}+1) / 2$ and $\left(v_{2}, v_{2}^{\prime}\right)$.

For any $\mathrm{i}$, where $1 \leq \mathrm{i} \leq(\mathrm{m}+1) / 2$, $f^{*}\left(v_{2 i-1}, v_{2 i}^{\prime}\right)=\left|f\left(v_{2 i-1}\right)-f\left(v_{2 i}^{\prime}\right)\right|=|\mathrm{i}-(2 \mathrm{~m}+3-\mathrm{i})|$

$=|(q+2)-2 i|$ which is an odd number $\forall \mathrm{i}$ These $(m+1) / 2$ edges are labeled with numbers $q$, $\mathrm{q}-2, \mathrm{q}-4, \ldots,(\mathrm{q}+3) / 2$.

For any $\mathrm{i}$, where $1 \leq \mathrm{i} \leq(\mathrm{m}+1) / 2$, $f^{*}\left(v_{2 i-1}^{\prime}, v_{2 \mathrm{i}}\right)=\left|f\left(v_{2 i-1}^{\prime}\right)-f\left(v_{2 \mathrm{i}}\right)\right|=$ $|(m+1+\mathrm{i})-(\mathrm{m}+2-\mathrm{i})|=|2 \mathrm{i}-1|$ which is an odd number $\forall \mathbf{i}$

These $(m+1) / 2$ edges are labeled with numbers $1,3,5$, ..., $(\mathrm{q}-1) / 2$.

Let $\mathrm{j}=\mathrm{i}+1$, for any $\mathrm{i}$, where $1 \leq \mathrm{i} \leq(\mathrm{m}+1) / 2$,

$f^{*}\left(v_{2 \mathrm{i},} v_{2 j-1}^{\prime}\right)=\left|f\left(v_{2 \mathrm{i}}\right)-f\left(v_{2 j-1}^{\prime}\right)\right|$

$=|(m+2-i)-(m+1+j)|$

$=|2 \mathrm{i}|$ which is an even number $\forall \mathrm{i}$

These $(m-1) / 2$ edges are labeled with numbers $2,4,6$, ..., $(\mathrm{q}-3) / 2$.

Let $\mathrm{j}=\mathrm{i}+1$, for any $\mathrm{i}$, where $1 \leq \mathrm{i} \leq(\mathrm{m}+1) / 2$, $f^{*}\left(v_{2 i}^{\prime}, v_{2 j-1}\right)=\left|f\left(v_{2 i}^{\prime}\right)-f\left(v_{2 j-1}\right)\right|=|(2 \mathrm{~m}+3-\mathrm{i})-\mathrm{j}|$ $=|(q+1)-2 i|$ which is an even number $\forall i$ These $(m-1) / 2$ edges are labeled with numbers $q-1, q-3$, $\mathrm{q}-5, \ldots,(\mathrm{q}+5) / 2$ which are distinct even number.

For the edge $\left(v_{2}, v_{2}^{\prime}\right)$,

$f^{*}\left(v_{2}, v_{2}^{\prime}\right)=\left|f\left(v_{2}\right)-f\left(v_{2}^{\prime}\right)\right|=|(m+2)-(2 \mathrm{~m}+3)|$

$=(q+1) / 2$ which is also an even number.

Thus the edges $\left(v_{1}^{\prime}, v_{2}\right),\left(v_{2}, v_{3}^{\prime}\right),\left(v_{3}^{\prime}, v_{4}\right), \ldots,\left(v_{m+1}^{\prime}, v_{m+1}\right)$ receive consecutive numbers such as $1,2,3, \ldots,(\mathrm{q}-1) / 2$ as labels; the edge $\left(v_{2}, v_{2}^{\prime}\right)$ receives the number $(q+1) / 2$ as label and the edges $\left(v_{m+1}^{\prime}, v_{m}\right),\left(v_{\mathrm{m}}, v_{m-1}^{\prime}\right),\left(v_{m-1}^{\prime}, v_{\mathrm{m}-2}\right)$

\section{Annexure II. Skolem graceful labeling.}

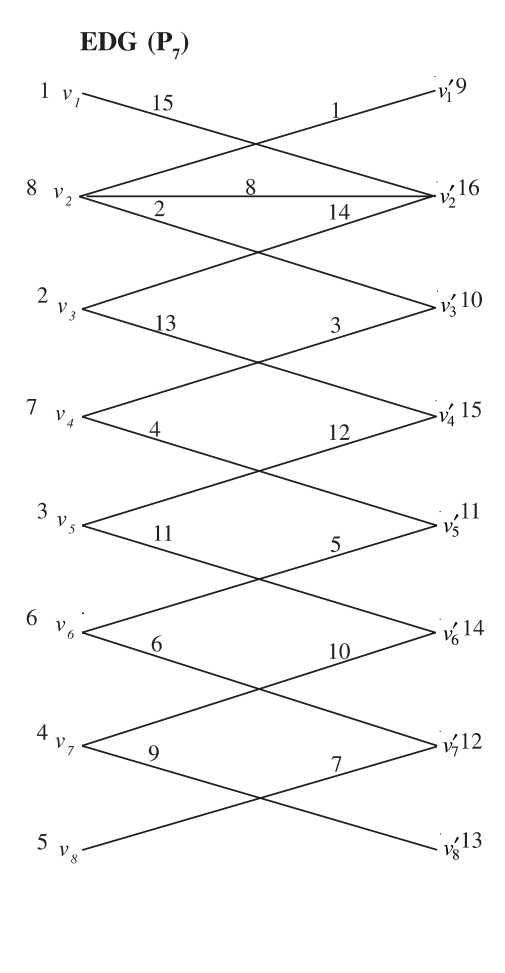

$\operatorname{EDG}\left(\mathbf{P}_{8}\right)$

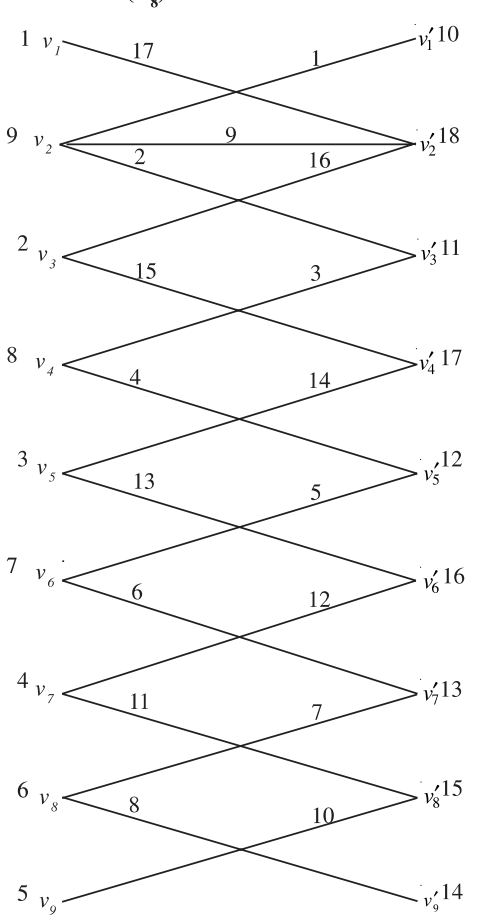

\section{References}

1. Gallian JA (2010) A dynamic survey of graph labeling. Elec. J. Combin. 17, \# DS6.

2. Golomb SW (1997) How to number a graph, in graph theory and computing, RC Read, ed., Academic press, NY. pp:23-37.

3. Lee SM, Wang S and Wui I (1988) On Skolemgracefulness of 4 stars. Congr. Number. 62, 235-239.

4. Rosa A (1967) On certain valuations of the vertices of a graph, theory of graphs (Int. Symp. Rome, July 1966), Gordon and Breech NY and Dunod paris. pp:349-355.

5. Thirusangu K, Ulaganathan PP and Selvam B (2010) Cordial labeling in duplicate graphs. Int. J. Computer Math. Sci. Appl. 4(1-2), 179-186.

6. Youssef MZ (2003) New families of graceful graphs. Ars. Combin. 67, 303-311.

,..., $\left(v_{2}^{\prime}, v_{1}\right)$ receive consecutive numbers such as $(q+3) / 2,(q+5) / 2, \ldots, q$ as labels.

That is $f^{*}(E)=\{1,2,3, \ldots, q\}$ which are all distinct and hence EDG $\left(P_{m}\right)$ is Skolem graceful.

Illustration: Skolem-graceful labeling for the graph

$\operatorname{EDG}\left(\mathrm{P}_{7}\right)$ and EDG $\left(\mathrm{P}_{8}\right)$ are shown in the annexure II. 